\title{
Assessment 100\% Supported by ICT: Possibilities Offered and Risks
}

\author{
$\underline{\text { doi:10.3991/ijet.v5i3.1302 }}$ \\ P. Teherán, O.Almanza and H. Mendoza \\ Universidad Nacional de Colombia, Bogotá, Colombia
}

\begin{abstract}
After the launching of a Fundamentals of Physics course offered for different campuses of the National University of Colombia in blended learning mode, various experiences were collected in a virtual assessment that were supported $100 \%$ by ICT. We implemented an evaluation system that consists of different categories ranging from traditional examinations, partial examinations, final examinations, workshops, quizzes, attendance, and duties and forums, all evaluated online. In particular, random blocks of questions were used for examinations taken from large databases, built especially for this purpose, on the order of $\mathbf{1 0 0}$ per chapter. We comment on the results achieved with the implementation of the evaluation system proposed, in addition to the possibilities offered and the risks they present.
\end{abstract}

Index Terms-Blended Learning, Evaluation, ICT, Online assessment.

\section{INTRODUCTION}

With the advent of new information and communication technologies (ICT), the significant advance of the integration of computational tools by communication, storage, data management, and image / voice devices (mobile phones, PDAs, the iPhone, etc.) coupled with the crisis shown in the study of Physics, make the utilization of these technologies relevant in the educational field. Of particular interest in the professorial community, likewise in governmental agencies, is the subject of the quality and relevance of assessment strategies, follow-ups, and evaluations in virtual learning environments.

Some authors have promoted [2] the enormous potential that ICT possess for use in learning management within the framework of the European Higher Education Area (EHEA), as well as in projects funded by governmental agencies in Canada, Chile, and Spain among others. Various LMS (Learning Management/Mediated System) type platforms are available at this date, many of which are free and others licensed. Of special interest are Blackboard, WebCT, Moodle, Claroline, Sakai, and Manhattan. However, few studies emphasize concrete evaluation strategies applied to both on-site learning and blended or completely online learning to display specific results.

The following stimulating questions have guided the envelopment of this initiative.

1. Is the assessment of comprehension possible for $100 \%$ on-line learning courses?

2. How can we be sure about who is behind the computer completing an assessment?

This article's aim is to illustrate the assessment approach developed by the Group of Applied Physics and
Lev Vígodsky in one of their lines of research, "TeachingLearning, Assessment and Physics Didactics”.

\section{ASSESSMENT SYSTEMS AND RESULTS.}

Our approach to this topic is based on the postulates of the Continuous and Personalized Evaluation (CPE [3],[4],[5]) which emphasizes the social character of the process of learning expressed by Lev Vigotsky. Also, we advocated the democratization of the assessment process with the assistance of ICT. The following (see Table 1) shows our approach.

\section{A. Assessment Democratization}

With the use of LMS Blackboard we organized a survey with the object being that students are able to choose two relevant aspects of the assessment process, namely:

1. The most convenient date to establish the weighted values for seven assessment categories as shown in Fig. 1.

2. The values weighting the 7 categories Fig. 2 of the cumulative assessment between a ranges established by the teacher in charge as shown in Fig. 3.

TABLE I.

QUALITY OF LEARNING ACCORDING TO PROCESSES AND EXPERIENCES

\begin{tabular}{|l|}
\hline Most people learn ... [6] \\
\hline $10 \%$ of what one reads \\
$20 \%$ of what one hears \\
$30 \%$ of what one see \\
$50 \%$ of what one sees and hears simultaneously \\
$70 \%$ of what one speaks with others \\
$80 \%$ of what one uses and does in real life \\
$95 \%$ of what one teaches others \\
\hline
\end{tabular}

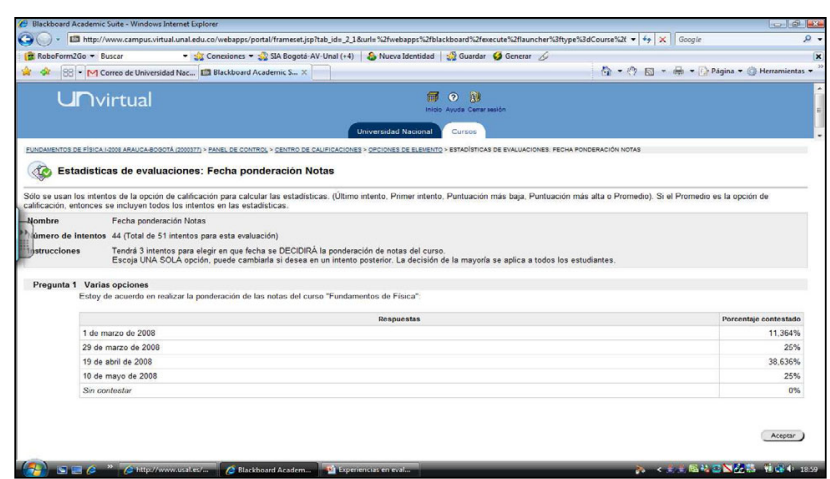

Figure 1. Results of the survey to establish the most appropriate date for appraisal the weighted values 


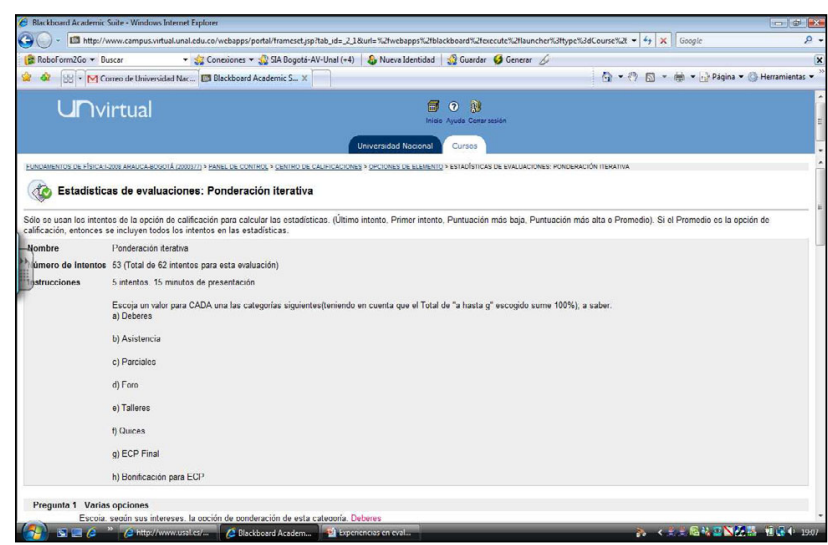

Figure 2. The 7 categories of the cumulative assessment

\begin{tabular}{|lll|}
\hline \multicolumn{3}{c}{ Final Weighting } \\
Category & weighted & vote \\
- Duties & - $10 \%$ & $46,296 \%$ \\
- Attendance & - $10 \%$ & $79,63 \%$ \\
- Exams & - $20 \%$ & $27,778 \%$ \\
- Forums & - $10 \%$ & $46,296 \%$ \\
- Workshops & - $10 \%$ & $44,444 \%$ \\
- Quizzes & - $15 \%$ & $75,926 \%$ \\
- ECPFinal & $-25 \%$ & $35,185 \%$ \\
- Bonus & $-0,15$ & $50 \%$ \\
\hline
\end{tabular}

Figure 3. The values weighting the 7 categories of the cumulative assessment

\section{B. Assessment Tools}

Activities were grouped into different sets aimed at monitoring the student-centered learning processes, promoting self-evaluation, stimulating peer evaluation between students and promoting the collective evaluation of the professor/tutor team. These sets, hereinafter called Categories, were as follows:

\section{1) Face-to-face and Online Attendance}

Due to the characteristics of the blended learning format of the course, the statutory regulation of an $80 \%$ minimum attendance record to scheduled classes by the university and the distinctiveness of classes taught by Telepresence or online attendance, this innovation to the assessment process was introduced. This consists of the creation of an online test, as shown in Fig. 4 that can only be accessed using a password that is announced at the time of the class. For purposes of control, a group sanction is imposed in case the number of accesses to the test exceeds the total amount of each class student present.

\section{2) Duties}

For the proper development of the classes it is important to establish activities designed to maintain a high rate of study, this category includes rubric type tests that support a self assessment process, with which one monitors before and after the class session, the levels of understanding of the base terminology of the schedule. In addition, to promote interpersonal relation of students of different campuses, the filling of forms with essential information such as email address and a digital photo of the student is required. The presentation of practice tests as a basis for comparison with the final examination are also a requirement.

\section{3) Forums}

This format of asynchronous collaborative work is useful for the introduction of different aspects to the formal curriculum of the provided subject and the clarification of doubts and resolution of questions during after hours. The difficult task of quantification has been addressed from the perspective of the mutual evaluation of the members of the course under the strict supervision of tutorial team. As an innovation to the evaluative process, we introduced a grade to each student proportional to the maximum number of publications by student participants, the relative weight of the average of the grades of the co-evaluation (Quality) and the Participation tending towards a greater weighting of quality. Another weighted aspect that we have included is the Relevance of the participations that are measured with an indicator of the number of participations coalesced around another that acts as revealer of the published answers. The proportion of Participation/Quality/Relevance chosen by students for several semesters has shifted towards the relationship of $20 \%$ / $50 \%$ / $30 \%$ weighting for each forum.

\section{4) Exams}

Online assessments have allowed greater segmentation of the program and the realization of open ended answer questions during after hours. Among the innovations introduced in the assessment process there is the possibility of presenting the tests in windows of 24 to 72 hours which offers flexibility in the student's schedule. Additionally, there is the option for several attempts to the complete set of problems while only grading the last attempt, which decreases the anxiety typical of students presenting traditional written tests in which errors cannot be removed. The above is valid when the quantity of questions exceeds the total number of students registered in the class, this way the tests are generated with a random selection algorithm for each item of the examination. For the present research, the bank of questions was 3,600 questions for 36 items of assessment. The maximum time of presentation for each exam did not exceed 30 minutes.

\section{5) Workshops}

Another online innovation for student assessment has been the introduction of group activities for solving problems with the help of Java applets. For these activities, the assigned task consists in solving a laboratory problem in which students can do measurements within a simulation.

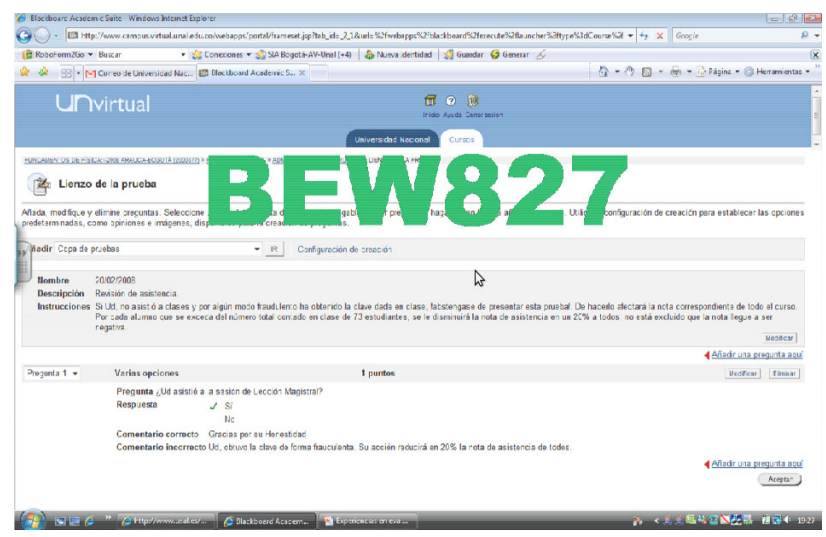

Figure 4. The attendance monitoring 
The reports are compared with the help of the Save Assign tool which registers matches found in the set of reports submitted as a solution to the workshop. Criteria are imposed for the maximum percentage of matches within texts and data for the reports which limits the copying typical in laboratory reports.

6) Quizzes

This is the classic multiple-choice quiz common in virtual environments. They are realized from the solutions of the workshops.

\section{7) Final Exam}

This is equivalent to the classic final exam with the difference that it is performed online and outside the classroom. This is done using the same bank of questions, 3,600 in total. It is a random test that sifts through all of the topics and consists of 36 questions, one per topic. The low probability of repetition makes its implementation, given that each exam generated is different for each student. It also offers the possibility for the student to present several attempts and in a typical time window 2 to 3 days. The average maximum permitted time is 2.5 minutes for each open ended response question.

\section{RISKS AND POSSIBILITIES}

Virtual assessment with the range of previously described alternatives is a reality. Among their most important potential benefits is the customization that will be possible with the creation large banks of various types, from open ended response questions, to questions generated by algorithms, random in context, values and other details. Flexibility in their application allows a greater democratization of the assessment process which will require conceptual changes in forms of application of tests and their significance. The risks inherent in the management of databases of great importance remain latent, however, the enormous diversity of random selection from large banks of questions makes more remote the possibility of simple copying between students.

\section{CONCLUSIONS}

We successfully launched a system of monitoring and evaluation of a physics course in blended learning format supported with classes by Telepresence. We found that the variety of forms of assessment makes the possibility of copying in the online assessment processes remote when using large banks of questions. The flexibility of application of online and after hours tests is an option that decongests tight curriculums of classes.

\section{REFERENCES}

[1] http://iopireland.org/activity/education/Science on Stage/Physics _on_Stage_1/page_19123.html

[2] M. Delgado-García, R. Borge-Bravo, J. García-Albero, R. OliverCuello, L. Salomón-Sancho, "Competencias y diseño de la evaluación continua y final en el espacio europeo de educación superior (Competencies and Design of the Continuous and Final Assesment in the European Higher Education Area)”, 2005, p. 1-176. Available: http://www.ub.es/eees/documents/pdfes/mec/competencias evaluacion eees mec.pdf

[3] P. Teherán, J.C. León, "Física conceptual en versión b-learning”, presented at the XIV Congreso Internacional de tecnología y educación a distancia, San José, Costa Rica, 2008.

[4] P. Teherán; C. A. Cuesta, "Valoración de cambios conceptuales en estudiantes de Física I (Evaluation of Conceptual Changes of Physics I Students)”, in Experiencias Significativas en Innovación Pedagógica, G. Hernández and F. A. Vargas, Eds. Bogotá, Colombia: Unibiblos, 2006, pp. 196-205. Available: http://disi.unal. edu.co/ gjhernandezp/esip/esip.pdf

[5] V. García-Hoz, ¿Qué es la educación personalizada? (What is Personalized Education?). 2nd ed.-Buenos Aires: Docencia; 1981, pp 46.

[6] Table attributed to William Glasser according to BIGGS, quoted in Association for Supervision and Curriculum Development Guide 1988 (BIGGS, John: “Quality in University Learning”, p. 106)

\section{AUTHORS}

P. Teherán is with the Universidad Nacional de Colombia, Physics Department, Carrera 30 \# 45-03, Bogotá, Colombia (e-mail: pdteherans@bt.unal.edu.co).

O. Almanza is with the Universidad Nacional de Colombia, Physics Department, Carrera 30 \# 45-03, Bogotá, Colombia (e-mail: oaalmanzam@unal.edu.co).

H. Mendoza is with the Universidad Nacional de Colombia, Statistics Department, Carrera 30 \# 45-03, Bogotá, Colombia (e-mail: (hmendozar@unal.edu.co).

This work was supported in part by the Universidad Nacional de Colombia, Facultad de Ciencias.

Manuscript received 15 April 2010. Published as resubmitted by the authors August $4^{\text {th }}, 2010$. 